\title{
Essentials public health functions and public health genomics in Ecuador
}

\author{
Funções essenciais de saúde pública genômica em saúde pública no Equador \\ Funciones esenciales de salud pública y genómica de salud pública en Ecuador
}

Received: 04/06/2021 | Reviewed: 04/11/2021 | Accept: 04/12/2021 | Published: 04/25/2021

Fabricio González-Andrade

ORCID: https://orcid.org/0000-0002-2091-9095 Universidad Central del Ecuador, Facultad de Ciencias Médicas, Ecuador E-mail: jfgonzalez@uce.edu.ec

Gabriela Aguinaga-Romero

ORCID: https://orcid.org/0000-0002-6274-2195

Universidad Central del Ecuador, Facultad de Ciencias Médicas, Ecuador E-mail: maguinaga@uce.edu.ec

\begin{abstract}
Aim: This paper aims to analyze the EPHF in MG in Ecuador as a framework for integrating it into clinical practice. It also aims to contribute to the scientific and social debate on the MG role, considering it the most advanced science field today. Context: the Essentials Public Health Functions (EPHF) are actions for specific purposes necessary to achieve the central objective of Public Health ( $\mathrm{PH})$, which is to improve, promote, protect, and restore the population's health through collective action. Medical Genetics (MG) and Genomics are still in construction between public policies, especially in developing countries, and deserve an in-depth approach in this context. Discussion: We understand collective health as an inter-institutional and interdisciplinary social practice, which involves both the State and civil society, aims at protecting and improving people's health. It implies population or community interventions; it includes the responsibility to ensure access and health care quality. Within this practice are the EPHF, defined as actions carried out for specific purposes necessary to achieve the PH Practice's central objective. Each function's operation depends on a sufficient definition of contents, objectives, and activities and on the specific assignment of who is responsible for their execution. Conclusion: The EPHF guides public health policies in Latin America and Ecuador. From this perspective, medical genetics and genomics must be included as a priority in the country's public policy. In this review, we propose the activities to be implemented in this context. This challenge requires political and scientific leadership.

Keywords: Essential public health functions; Ecuador; Medical genetics; Public policies; Healthcare.
\end{abstract}

\section{Resumo}

Objetivo: este artigo tem como objetivo analisar as FESP em MG, no Equador, como uma estrutura para integrá-la à prática clínica. Visa também contribuir para o debate científico e social sobre o papel do MG, considerando-o o campo mais avançado da ciência na atualidade. Contexto: as Funções Essenciais de Saúde Pública (FESP) são ações com finalidades específicas necessárias para atingir o objetivo central da Saúde Pública (AP), que é melhorar, promover, proteger e restaurar a saúde da população por meio da ação coletiva. A Genética Médica (MG) e a Genômica ainda estão em construção entre as políticas públicas, principalmente nos países em desenvolvimento, e merecem um aprofundamento neste contexto. Discussão: Entendemos a saúde coletiva como uma prática social interinstitucional e interdisciplinar, que envolve o Estado e a sociedade civil, que visa proteger e melhorar a saúde das pessoas. Implica intervenções na população ou na comunidade; inclui a responsabilidade de garantir o acesso e a qualidade dos cuidados de saúde. Dentro dessa prática estão as FESP, definidas como ações realizadas com finalidades específicas necessárias para atingir o objetivo central da Prática de HP. O funcionamento de cada função depende de uma definição suficiente de conteúdo, objetivos e atividades e da atribuição específica de quem é responsável pela sua execução. Conclusão: As FESP orientam as políticas públicas de saúde na América Latina e no Equador. É imprescindível que, desse ponto de vista, a genética médica e a genômica sejam incluídas como prioridade nas políticas públicas do país. Nesta revisão, propomos as atividades a serem implementadas neste contexto. Este desafio requer liderança política e científica.

Palavras-chave: Funções básicas de saúde pública; Equador; Genética médica; Políticas públicas; Assistência médica.

\section{Resumen}

Objetivo: Este trabajo tiene como objetivo analizar las FESP en MG en Ecuador como marco para su integración en la práctica clínica. También pretende contribuir al debate científico y social sobre el papel de la MG, considerándolo el campo científico más avanzado en la actualidad. Contexto: las Funciones Esenciales de Salud Pública (FESP) son acciones con fines específicos necesarios para lograr el objetivo central de la Salud Pública (PH), que es mejorar, promover, proteger y restaurar la salud de la población a través de la acción colectiva. La Genética Médica (MG) y la Genómica aún se encuentran en construcción entre las políticas públicas, especialmente en los países en desarrollo, y merecen un enfoque en profundidad en este contexto. Discusión: Entendemos la salud colectiva como una práctica 
social interinstitucional e interdisciplinaria, que involucra tanto al Estado como a la sociedad civil, tiene como objetivo proteger y mejorar la salud de las personas. Implica intervenciones poblacionales o comunitarias; incluye la responsabilidad de asegurar el acceso y la calidad de la atención médica. Dentro de esta práctica se encuentran las FESP, definidas como acciones realizadas con fines específicos necesarios para lograr el objetivo central de la Práctica de PH. El funcionamiento de cada función depende de una definición suficiente de contenidos, objetivos y actividades y de la asignación específica de quién es el responsable de su ejecución. Conclusión: Las FESP orientan las políticas de salud pública en América Latina y Ecuador. Es fundamental que desde este punto de vista, la genética médica y la genómica sean incluidas como una prioridad en la política pública del país. En está revisión, proponemos las actividades a implementar en este contexto. Este desafío requiere liderazgo político y científico.

Palabras clave: Funciones básicas de salud pública; Ecuador; Genética médica; Políticas públicas; Cuidado de la salud.

\section{Introduction}

\section{Essentials Public Health Functions}

Public Health (PH) implies collective health, an inter-institutional and interdisciplinary social practice that involves both the State and civil society and aims to improve, promote, protect, and restore the population's health through collective action. It does not only means population or community interventions. It includes the responsibility to ensure access and quality of health care. Within this practice are the Essentials Public Health Functions (EPHF), defined as actions for specific purposes necessary to achieve PH's central objective. Each function's operation depends on a sufficient definition of contents, objectives, and activities and the specific assignment responsible for their execution (Conejero et al., 2013).

The EPHF includes diagnosis, evaluation, analysis, and monitoring of the health situation. Besides, surveillance of PH, research, control of risks and damages in PH. Another EPHF is health promotion, citizen participation in health, development of policies, and institutional capacity for planning and management. Strengthening the institutional capacity for regulation and oversight in PH matters; evaluation and promotion of equitable access to necessary health services; human resource development and training in PH; guarantee and improvement of the quality of individual and collective health services; research and reducing the impact of emergencies and disasters on health (Zwanikken et al., 2014).

We approached the EPHF, considering them as the mandate of the health authority and as a set of activities organized by the public administration to improve individual's wellbeing (Aswini \& Varun, 2010). This document proposes to show the possible activities to implement for Medical Genetics (MG) in Ecuador from EPHF.

\section{Defining Medical Genetics}

In current times and with the immense scientific and technological progress, many of the health approaches are inter and multidisciplinary. These approaches facilitate the management and administration of health as they achieve the integration and rational use of public resources. A good example is integrating Genetics in public management and development processes (Battista et al., 2012). We understand Medical Genetics (MG) as the application of genetics in medicine and include all Genomics. In this regard, MG has a wide and varied application that includes different individual areas such as clinical genetics and laboratory genetics. Laboratory genetics addresses at least three significant subcomponents, biochemical genetics, molecular genetics, and cytogenetic. Knowledge of molecular biology and genomics continues to expand rapidly, promising numerous opportunities to improve health. However, an essential aspect of genomic medicine's success relates to understanding and accepting the public and the community in general (Christianson et al., 2004). See Figure 1. 
Figure 1. Reasons why Genetics has not adequately implemented in Public Health in Ecuador.

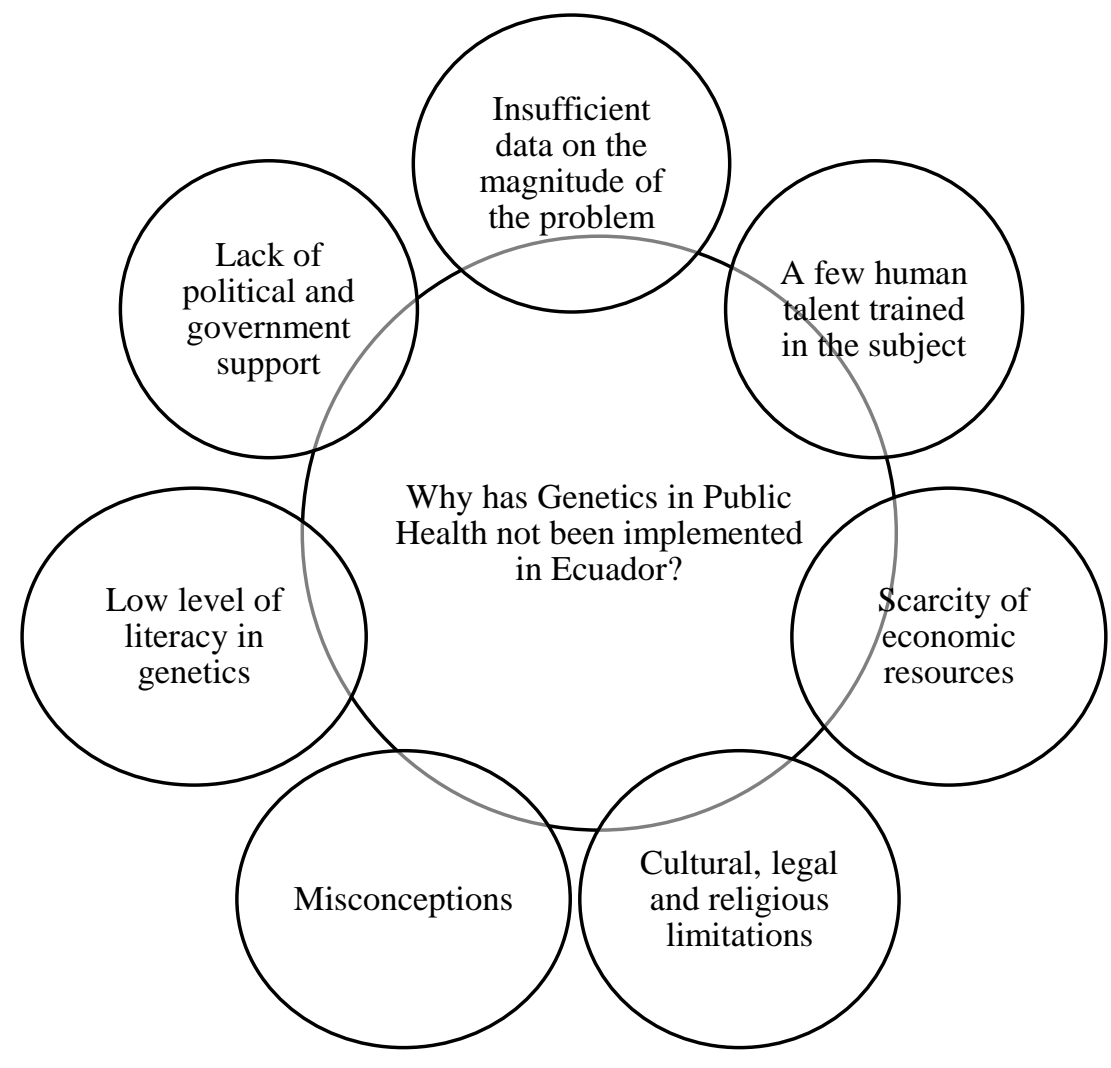

Source:Authors.

Genetics includes other multidisciplinary areas such as forensic genetics, evolutionary genetics, comparative genetics, genetic anthropology, developmental genetics, optogenetics, epigenetics, among others that appear every day with this new integrative approach between science, medicine, and the social field. Other subspecialties such as oncogenetic, molecular medicine, molecular microbiology, immunogenetics, and genetic epidemiology have also appeared with medical science development. This approach shows MG's importance in PH and justifies why it is essential to talk about this topic (Rogowski et al., 2009). Indeed, changes occur in the provision of genetic services and the redefinition of professional roles, with a strong tendency to integrate genetic medicine in other specialties and primary care (Knottnerus, 2003).

Human Genetics, the highest field of genetics, studies the bases of biological variability and inheritance in the human species. Therefore, it exceeds the scope of MG since its objective focuses on its medical applications. This idea means that MG focuses on possible applications that improve people's health. Genetic medicine, like personalized medicine, is a recent term within MG to highlight the direct application of the fundamentals and methods of genetics in the diagnosis and treatment of diseases.

On the other hand, developed countries' experience indicates that 400 to 500 genetic consultations generate annually for every million inhabitants. It estimates that there should be a highly complex regional genetics center for at least every 5 million inhabitants, with a service capacity of at least 3,000 consultations per year. This issue makes it essential to discuss genetics in the context of PH. Within the MG, services are the clinical and laboratory diagnosis of CD and diseases of genetic origin, genetic counseling, pre-conception, prenatal, neonatal, and perinatal diagnosis, carrier detection, population genetic studies, and adequate reference for the treatment and follow-up of diseases diagnosed with genetic tests (Kaye, 2012).

$\mathrm{PH}$, especially in Europe, has an indispensable component called Community Genetics, defined by the WHO as the art and science of the practical and responsible application of genetics related to the health-disease process; as well as the application 
of genomic technology in human populations, also called communities, always seeking the most significant benefit for people (Ten Kate et al., 2010). It is, therefore, the basis for the provision of services and comprehensive care in this field. The objective of Community Genetics according to the Global Strategy for the Prevention and Control of No communicable Diseases (NCDs), in developing countries is to prevent $\mathrm{CD}$ and diseases of genetic origin in the general population and to provide genetic services in the community, both for individuals and families (Ten Kate, 2005). In this area, the term prevention indicates implemented actions to reduce the prevalence at birth of congenital-metabolic disorders and the impact on genetic diseases, respecting voluntary reproductive decisions (Etchegary et al., 2015).

In recent years, a new hybrid specialty of Genetics and PH has emerged. PH Genomics, a term used primarily in the USA, is defined as apply advances in molecular biotechnology and genetics to improve PH and prevent disease. Community genetics, a term used primarily in Europe, has been defined as a genetics branch with both service and science components. The services component seeks to integrate genetic services into community interventions. The science component encompasses the research necessary to develop and evaluate services (Brand et al., 2008; Halliday et al., 2004). We consider both terms similar in this review.

\section{Genetics in Ecuador}

Several reasons do not allow developing Genetics sufficiently in Ecuador. Indeed, there is insufficient data on the magnitude of the problem; there is a low level of literacy on this subject; misconceptions about genetic diseases; cultural, legal, religious limitations; lack of economic resources; a few human talents trained in this subject; and lack of political and Government support (González-Andrade et al., 2010). See Figure 2.

Figure 2. Genetics Areas.

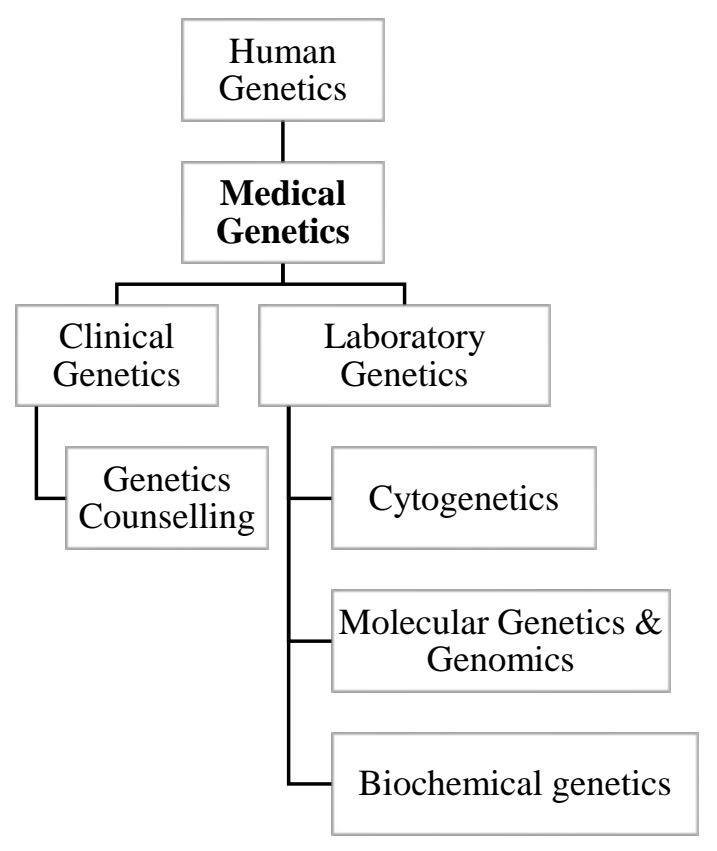

Source:Authors.

This review aims to analyze the EPHF in MG in Ecuador to integrate MG in the clinical practice. It also aims to contribute to the scientific and social debate on MG's role, considering it as the most advanced science today in the context of PH. 


\section{Methods}

Qualitative perspective: the purpose is to critically and reflectively assess the possible interventions in public health policy related to the Essentials Public Health Functions and Public Health Genetics and Genomics in Ecuador, including legal, fiscal, structural, organizational, environmental, and public policy interventions, such as the organization of health services, and changes in social welfare policies. This analysis reflects the critical opinion of the authors from the perspective of scientific positivism.

Study design: This is a quantitative evaluation that involved the study and documentary analysis of recent documents, using data from current and recent events to learn how intentions and past events were related to each other due to their meaning and value. We reviewed documents considering the context in which they were created, about people, places, and events that present learning opportunities.

Scenario: Ecuador, 2019 and 2020.

Characteristics of the researchers: the researchers are academics, linked to universities with no direct relationship with any government agency. They do not have any direct conflict of interest, although some participated in public management years ago.

Data collection methods: We used two strategies: a) Analysis of official published documents of the Ministry of Health, b) Documentary research of other related published documents on the proposed topic.

\section{Results and Discussion}

\section{EPHF 1: Monitoring and analysis of the population's health situation}

Health authorities identified genetic origin disease as a PH problem in Ecuador only a few years ago, when infectious and nutritional diseases were controlled. Efforts to develop capacities in this field were restricted for a long time. In the beginning, Ecuadorian universities leader this entire field, followed by isolated efforts at the private medicine level. Researchers estimate that $80 \%$ of all diseases have a genetic component, influenced to a greater or lesser degree by the environment (GonzalezAndrade et al., 2012). Genetic diseases are a significant health problem and are responsible for $70 \%$ of admissions in children's hospitals and $95 \%$ in the case of chronic diseases. It estimates that some genetic origin disease (Burton PR et al., 2006) affects $8 \%$ of the population over 25 years.

Congenital Defects. In Latin America, it estimates that up to 7\% of newborns (NB) have a congenital defect (CD); they cause $20 \%$ of deaths in the postnatal period and occupy between the 2nd and 5th place among the causes of death of children under 1 year of age in Ecuador (González-Andrade \& López-Pulles, 2012).

Disability. According to the Manuela Espejo Solidarity Mission in 2010, we identified 293,743 people with a visible disability at the national level. Of these, 71,417 have an intellectual disability, and 20,285 individuals presented disability due to prenatal genetic origin. At least $30 \%$ of intellectual disabilities are of a genetic cause, and we detected $42 \%$ at the prenatal and neonatal levels. The data reported by this program indicate that the prevalence of disability in the country is 2.43 per 100 inhabitants (Monje-Vargas 2013).

The goals to achieve in this EPHF are to analyze incidence, mortality, and morbidity data to prevent and reduce the disease's burden. Also, associate the data with genetic predisposition and environmental triggers; identify opportunities to include genetic information in existing health programs. And develop data collection systems that can be integrated with existing data 
systems, e.g., birth defect registries, vital statistics, birth and death certificates, cancer registries, laboratory reports; identify communities that could benefit from genetic information and interventions; develop a system to analyze the validity and usefulness of genetic tests.

Proposed action: Carry out an accurate and updated study of the prevalence and epidemiology of diseases of genetic origin in Ecuador

\section{EPHF 2: PH surveillance}

It includes the PH infrastructure designed to conduct population screening, case detection, and epidemiological research in general. A registry is a standardized collection of information about a group of people, such as those living with the same disease, used for a variety of specific purposes. A registry is a powerful tool for collecting information about patients diagnosed with the same rare disease or birth defect. One difficulty in learning more about the disease is finding enough people eligible to participate in research studies. The more participants in a study, the more influential the results are (Woodhouse et al., 2014).

Ecuador needs an integrated epidemiological surveillance system creating the Ecuadorian Registry of Congenital Malformations (REMAC), the Ecuadorian Registry of Rare Diseases (RECER), and The Ecuadorian Registry of Hereditary and Familial Cancer (RECAF). REMAC has to be carried out in coordination with the National Department of Epidemiological Surveillance of the Ministry of Health $(\mathrm{MoH})$. Software and an information repository allow the reporting of cases from any part of the country. It develops with two components: development of software and an information repository that allows reporting cases from any part of the country and conducting short training courses. Our team has published several papers in this regard. There are essential experiences in this area (Castilla \& Orioli, 1986; Smerecnik et al., 2009).

Likewise, RECER aims to identify all diseases of low prevalence diseases, defined as a disease with a prevalence of 1 in 10,000 individuals in Ecuador. Rare means disease can only affect a limited number of people. Ultra orphans diseases in our country are diseases with a prevalence of less than one per 50,000 individuals. They are diseases generally of genetic origin, of chronic, progressive, a degenerative course with high morbidity and mortality and a high degree of physical, mental, behavioral, and sensory disability, which can compromise the autonomy of patients; highly complex, diagnostic, prognostic and therapeutic; and that require permanent treatment, monitoring, and multidisciplinary intervention. When we create a rare disease registry, we bring together the entire community, including patients, caregivers, physicians, researchers, and industry. Understanding the diverse needs of all members of the rare disease community is vital so that patients and caregivers can join physicians, researchers, and industry.

The RECAF aims to identify all cases of hereditary cancer. About 5 to 10 percent of cancers are hereditary and familial. In these cases, an individual inherits a copy of a growth control gene with a mutation from one parent and a functional copy of the same gene from the other parent. The gene with the mutation is called the cancer susceptibility gene. Since the cancer susceptibility gene is inherited, it is found in every cell in the body, but the gene's working copy makes each cell function properly. However, if a mutation damages the working copy of the gene in a cell, that cell can lose its growth control and become cancerous. Therefore, people who inherit a gene for cancer susceptibility are much more likely to develop certain cancers in their lifetime.

Hereditary cancers are generally significantly different from non-hereditary cancers. The heredity way cancers run in the family indicates whether individuals of the same family have the same cancer type. Hereditary cancer includes two or more relatives with the same type of cancer, on the same side of the family; several generations affected; early ages of a cancer diagnosis; individuals with more than one primary cancer. Also, include the occurrence in a family of cancers that are known to be genetically related, such as breast and ovarian cancer, or colon and uterine cancer; the presence of physical signs known to be associated with hereditary cancer, such as moles and melanoma, or polyps and colon cancer, and certain rare types of cancer. 
The goals to achieve in this EPHF are identifying genetic risk factors to increase early intervention opportunities, reducing disease burden, and primary prevention of diseases throughout life. Also, identify environmental elements to which people may be particularly susceptible; develop a health promotion plan (social marketing) that allows citizens to use the Genetic information appropriately to reduce your risk of disease; train staff to assess genetic factors when investigating environmental health hazards and to create behavior change programs.

Proposed action: MoH has to implement REMAC, RECER, and RECAF within the epidemiological surveillance program.

\section{EPHF 3: Health Promotion}

WHO defines health promotion as the process that allows people to control their health. Universal Child and Family Health Services in Ecuador has the opportunity to carry out several evidence-based health promotion strategies that aim to encourage families to create attitudes, behaviors, and environments to promote optimal health for children.

Health promotion could carry out in a universal health service in several ways. These include providing information to parents through written or audiovisual resources; a discussion between the worker and the family, or demonstrating behavior that promotes health; role models through specifically established groups and other parents' experiences; and community awareness activities. There are four essential service elements related to health promotion: prevention of disease, injury, and illness; health education, anticipatory guidance, and parenting skills development; support that builds trust and is reassuring for mothers, fathers, and caregivers; and strengthening community capacity.

Promote disease prevention. Disease prevention is a fundamental component of the provision of child and family health services. The combination of monitoring child and family health while conducting preventive health activities offers early intervention, detection, and disease prevention. Disease prevention activities in genetics include adequate and timely immunization, promotion of nutrition and folic acid consumption, information on Sexually Transmitted Infections (STIs), promotion of child and family nutrition

Promote health education, anticipatory guidance, and development of parenting skills. Health education, advanced counseling, and parenting skills development are interrelated components of health promotion. These components can occur during individual contact with parents and caregivers or in a group setting. The benefits of a group delivery include peer support and profitable use of resources. Health education involves communication, information, and fostering the motivation, skills, and confidence necessary to improve health. These activities include support for mothers, fathers, and caregivers; maternal health; train parents committed to inclusive practice; facilitate peer support; and community capacity building.

The goals to achieve in this EPHF are to inform the general public and authorities about genetics and its impact on health; provide consistent information through a variety of focused health education programs so that informed decisions can be made about genetic health problems, and assess the community's needs for genetic information and services.

Proposed action: promote health education, anticipatory orientation, and parenting skills development, focusing on genetic origin diseases.

\section{EPHF 4: Social participation}

The community, civil society, health NGOs, and other local and sectional actors are a cornerstone of sustainability; for this, education, information, and communication tools are used for prevention and achieving the desired goals. The network extends coverage to the entire beneficiary population in the national territory. Incorporating a program like this, of national scope, guarantees that the $\mathrm{MoH}$ maintains their leadership in this matter, which generate social impact and guarantee a future equitable and supportive society, WHO believes that people-centered care is essential. We highlight interventions implemented 
at the global level and that the WHO considers effective. Among them are empowerment and participation of citizens through access to information, and the most effective interventions in this field seem to be in the areas of health education. Shared decision-making, self-care, and personal care planning for self-management of care and caregivers; social participation in policy development and oversight and decision-making; evidence shows that informed communities are better able to influence providers in achieving more people-centered care.

Patient and patient family associations. They represent patients and service users' vision at the national and local levels and offer an opportunity to support other patients and strengthen advocacy for people-centered care. These associations are commonly characterized as non-governmental and non-profit organizations, groups, or entities representing patients and their families' interests before different instances. In Ecuador exists several patient associations. The most known are the Association of Patients with Multiple Sclerosis and Demyelinating Diseases, the Association of Patients with Psoriasis, the Association of Parents of Children and Adolescents with Cancer, the Ecuadorian Foundation for Patients with Lysosomal Deposit Diseases, the Ecuadorian Hemophilic Foundation, Young People Against Cancer, the Ecuadorian Association to Help Patients with Rheumatic Diseases, the Ecuadorian Foundation for Cystic Fibrosis and, Suyana Foundation.

Patients associations propose the creation of social awareness about different diseases; the fight against the social stigma associated with them; the dissemination of information on the needs and priorities of patients; the work to improve the quality of life of patients through the demand for better health services; the promotion of new and improved technologies and treatments. Besides, they suggest generating collective spaces for self-care and self-help, education about self-care, the optimal way to manage the disease, and participation in forums on health issues. Other essential factors are the surveillance and monitoring of health systems reforms and their effect on patients' interests, monitoring the proliferation of medical therapies and new treatments, and, finally, researching different types of diseases with their respective scientific societies.

The goals to achieve in this EPHF are establishing effective communication with community members on genetic issues; establish a committee of responsible community leaders with equal levels of participation in decision-making to shape genetic policies and practices, and ensuring the relevance of genetic public policies and programs to serve and protect the communities.

Proposed action: Mobilize community alliances at the state and local level to identify and solve health problems at the genetic level and empower the community on these issues.

\section{EPHF 5: Development of policies, plans, and management capacity}

The National Public Policy on Genetics in Human Health is the instrument that the Ecuadorian Government proposed to organize Genetics and its actors in public and private practice and provide guidelines that allow progress towards equitable and timely access to specialized services. Unfortunately, this public policy never was implemented.

A second document, the Strategic Plan for Genetics in Human Health, based on four fundamental pillars: care, epidemiology, research, and teaching, was proposed. This document includes epidemiological surveillance and prevention of genetic, congenital, or metabolic diseases, prevention, and health promotion, particularly with teratogenic and genotoxic agents, prenatal and neonatal diagnosis as a prevention mechanism. This EPHF also includes PH management as a process of construction, implementation, and evaluation of organized initiatives designed to face population health problems and develop competencies for decision-making based on scientific evidence and that incorporate resource management, leadership skills, and effective communication.

The goals to achieve in this EPHF are applying population-based genetic information to state public policies and programs to improve individual and community health and develop a strategic plan to guide the integration of genetics into $\mathrm{PH}$ practices.

Proposed action: develop policies and practices that support individual and community health efforts, implement the 
National Genetics Policy in Human Health and the Strategic Plan of Genetics in Human Health in Ecuador.

\section{EPHF 6: Regulation and inspection in PH}

Several legal documents indicate the State's obligation to guarantee plans and programs related to MG that seek broad social inclusion. Some of them are mandatory to the $\mathrm{MoH}$ to create specialized Genetics services. See Figure 3.

The Organic Law on Disabilities, in its article 22, an article referring to Human Genetics and Bioethics, obligate to the national health authority, within the National Health System, regulates, to develop, and execute the National Human Genetics Program, focusing on prevention of disabilities, with unrestricted adherence to the principles of bioethics.

The current Organic Health Law says in article 69 that comprehensive care and control of non-communicable, chronic degenerative, congenital, hereditary diseases and problems declared a priority for $\mathrm{PH}$ has to be carried out through the coordinated action of all members of the National Health System, and the participation of the whole population. It includes researching its causes, magnitude, and impact on health, epidemiological surveillance, promotion of healthy habits and lifestyles, prevention, recovery, rehabilitation, social reintegration of affected people, and palliative care. Article 209 refers to specialized health services to exercise activities related to human genetics research and development. Article 210 authorizes the performance of genetic tests for transplants, mutational studies, genetic linkage, predictive tests of genetic diseases, tests to detect genetic predisposition to a disease, for therapeutic purposes, and others for genetic health purposes. Article 214 says that the national health authority seeks and promotes the integration and cooperative work of genetics research and development centers.

Figure 3. Legal regulations.

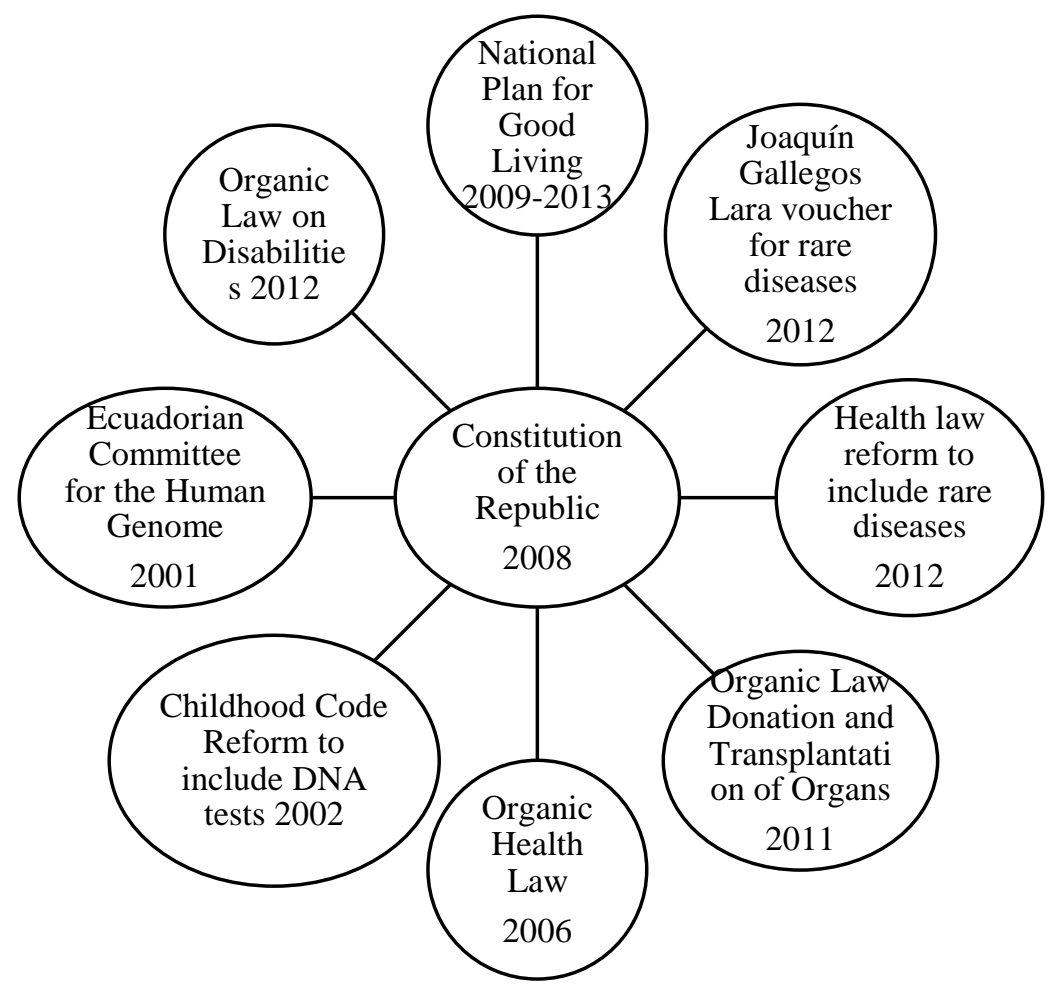

Source:Authors.

The Code of Childhood and Adolescence says in the sixth transitory provision that $\mathrm{MoH}$ has to create a Genetic Research Unit in which comparative examinations of band patterns or DNA sequences are practiced free of charge. Additionally, through ministerial agreement 1203, dated June 14, 2012, high subspecialty centers' typology is established, these being specific high subspecialty establishments that concentrate complex cases. The subspecialty that creates them must have the highest technology, 
and for their operation, they must have the special approval of the MoH through the Vice Ministry of Governance and Health Surveillance.

The Organic Law reforming the Organic Health Law published on January 24 of 2012 includes treating rare, orphan, and catastrophic diseases. The official register numbered 798 of September 27 of 2012 sets the inclusion criteria for diseases considered catastrophic, rare, and orphan and for beneficiaries of the Joaquín Gallegos Lara voucher. The Official register numbered 807 of October 10 of 2012; it is agreed to issue the general instructions for treating rare or orphan and catastrophic diseases.

Inspection and control. This activitie carries out follow-up activities through the $\mathrm{MoH}$ through scheduled visits to specialized hospital units to verify the equipment and facilities' appropriate use and the direct benefit that patients have received. The activities carried out at the first level of care are also evaluated through the Zonal Directions.

The goals to achieve in this EPHF are to develop legislation, statutes, and regulations that provide the optimal use of genetic information to improve health while protecting patients, clients, and consumers from the misuse of genetic information; and provide leadership and guidance for public policies on Genetics in Human Health.

Proposed action: Enforce laws and regulations that protect health and ensure patient safety.

\section{EPHF 7: Equitable access to health services}

Ecuador needs a network of specialized services in genetics. This network allows comprehensive solutions to the community's genetic health problems, thus improving their quality of life.

The objective is to integrate and consolidate the Renewed Primary Health Care Strategy at all healthcare levels; reorienting health services towards health promotion and preventing genetic diseases and also strengthening the recovery process, health rehabilitation, and palliative care to provide comprehensive, quality care and respect for people in their diversity and their environment, emphasizing the organized participation of social subjects.

The network tries to promote equity in health care to access genetic services as a vehicle for the entire population. Besides, to generate local actions to train professionals and generate epidemiological information to work by zones and districts through local actions, strengthen primary care, insert genetics in the first level of care at the mother-child level, and prevent CD and the promotion of health.

Medical Genetics Services. Although general physicians follow patients with genetic diseases, MG services tend to follow certain types of patients with complex problems requiring coordinated and specialized care, such as inborn errors of metabolism, skeletal dysplasias, chromosomal abnormalities, and others. These services' main objectives are the anticipatory guidance of problems, the patient's longitudinal treatment coordination, and genetic counseling. Attention to the psychosocial impact of genetic disease on the patient and the family as a unit is an essential aspect of genetic services. Levels of care organize these Genetics services.

At the first level of care, the comprehensive health team is in charge of promoting, preventing, and rehabilitating genetic origin diseases at the community and family level. Primary care physicians and Primary Care Technicians are in charge of capturing and monitoring cases of diseases of genetic origin. The activities they carry out are taking samples for neonatal screening for metabolic diseases, identifying patients for prenatal screening such as neural tube defects and aneuploidies, detecting patients with rare and low prevalence diseases, and searching and capturing cases of diseases. Of genetic origin, identification of intellectual disability of genetic origin, and referral to specialists in Clinical Genetics.

At the second level of care, specialist doctors are in charge of capturing, monitoring, and advising on cases of diseases of genetic origin. The activities carried out are the search and recruitment of patients, the timely detection of cases and families with diseases of genetic origin, the referral to specialists in Clinical Genetics, and the monitoring of intellectual disability. 
At the third level of care, the network creates outpatient services specialized in Genetics in the third level hospitals. The activities they carry out are timely detection of cases and families with diseases of genetic origin, the referral to specialists, the creation of Maternal-Fetal Medicine units, and high specialty diagnosis. The specialized hospital services must satisfy the zonal and regional demand for diagnosis and treatment services in Genetics. Also, make the clinical diagnosis of diseases of genetic, congenital, and metabolic origin, perform genetic counseling, request prenatal and neonatal genetic diagnosis; evaluate the newborn with these pathologies, provide medical consultations for Clinical Genetics and genetic counseling when required, diagnose low-prevalence diseases and promote their prevention whenever possible. They also have to inform and educate the community about the prevention of pathologies produced by teratogenic and genotoxic agents, support the treatment of disability of genetic origin through prevention activities and others inherent to their competence.

The fourth level of care comprises a Specialized Center in Genetics and Genomics, a specific high-subspecialty facility that concentrates on complex cases. In addition to direct actions on patients, it has other functions such as the genetic pathology registry, scientific research, specialized human resources training, and support for patient and family organizations.

The goals to achieve in this EPHF are creating provisions for high-quality, culturally competent genetic services for those who need them, ensuring that high-quality and clinically valid genetic testing is available, and developing genetic information and services culturally competent and effective in improving health.

Proposed action: link people to health services, including genetic services, and ensure the provision of health care at all possible levels

\section{EPHF 8: Human resources development}

Professionals in clinical genetics divide into two groups: medical specialists and non-specialist professionals. The first group involves medical geneticists and genetic counselors, and the second group is other health professionals who increasingly use genetics in routine care. The latter group includes general practitioners, other specialists, nurses, psychologists, social workers in patient care, biochemists, biotechnologists, and others in providing laboratory services.

Reconfiguration of professional roles. In the transition from traditional pediatric models to services tailored to adults' needs with genetic disorders or predispositions, genetic services have to extend beyond the pediatric model. A multidisciplinary team-based approach is also required, probably including an internist. Genetic counselors, considered relevant for integrating genetic services with primary care, should also be included. Nurses with specific training should be able to coordinate clinical services and establish links with other health resources. Therefore, the organization of genetic services offers at least two challenges: the redefinition and redistribution of roles and responsibilities in the context of an emerging paradigm for adult services that require collaboration between professionals and the exchange of experience between genetic professionals. Besides, genetic counselors and front-line doctors and nurses need on-site training.

The specialists. Medical Geneticist is a medical specialty in the USA, Canada, Australia, and some European countries for more than 30 years. In Ecuador, MG is a medical specialty, and professionals are scarce. USA recognized Genetic counseling as a profession USA since the early 1980s and has grown in recent years. On the contrary, one of the most severe problems is the lack of specialized personnel, medical geneticists, and genetic counselors, particularly in Ecuador. The professional workforce does not appear sufficient to meet the expected patient care in clinical genetics services for the next 20 years. It needs to assess factors as the low proportion of physicians who choose MG as their specialty and the lack of graduate programs in this field. In this sense, it is essential to educate and train students of non-genetic specialties in MG. This information includes aspects describing the structure, function, and transmission of the Human Genome and gene expression regulation. Genetic and epigenetic mechanisms as a basis for understanding human diseases. Students have to describe and differentiate the types and frequencies of genetic variations and how they arise and contribute to health and disease. To know the genetic or genomic basis 
of the disorders found in the specialty and if they follow a specific mode of inheritance; recognize, together with a family history or as an isolated presentation, and the subset of patients whose condition has a genetic basis. Also, as a monogenic condition and their appropriate genetic management; request tests using genetic technologies appropriately, interpret the results and apply them in the context of clinical management; and finally, to be able to communicate genetic and genomic concepts, probability information, and test results, to facilitate the commitment and choice of the patient and her family in the management of her condition.

Undergraduate education. It is indisputable that there should be a vital component of $\mathrm{MG}$, which includes training in Basic Genetics and Clinical Genetics, aimed at pediatric and adult patients within the curricula of careers in Medicine and Health. In Medical Schools, the Faculty of Medicine's basic study plan in Genetics, suggested by the ASHG and APHMG, has to be implemented. This document describes the necessary knowledge, skills, and behaviors that all medical students require in their future practice as physicians. The guidelines propose four ways to incorporate the teaching of genetics into the curriculum: a) MG provides a unique perspective on the human body's role in health and disease; it is both a clinical specialty and basic science. The teaching of MG should span the entire medical school curriculum and continue through the graduate years. b) MG must be explicitly included in the curriculum. Although other disciplines can teach some aspects of MG overlap, it is necessary to establish specific MG learning objectives. c) A well-qualified medical geneticist should have the authority and responsibility to implement each medical school's genetics curriculum. This responsibility should extend throughout the undergraduate medical curriculum and include participation in all courses that address genetic principles or disorders. d) MG can be taught effectively by a variety of methods and in various formats. Problem-based learning (PBL) is particularly well suited to MG because it involves integrating skills and knowledge from many fields. Genetics can also be taught in various clinical settings and at different clinical training points, depending on each school's particular circumstances. Specific clinical examples are essential, but the curriculum's focus should be on the examples' medical genetic principles.

The goals to achieve in this EPHF are create and maintain a competent workforce in MG; provide opportunities for today's workforce to obtain continuing education; create opportunities for continuing education for all health professionals, and incorporate current undergraduate and graduate students into MG education programs.

Proposed action: Ensure that all PH professionals are competent in MG, according to their professional level.

\section{EPHF 9: Quality guarantee}

This function includes promoting permanent quality assurance systems and developing a permanent monitoring system of the results of the evaluations made through these systems. It also includes facilitating the publication of standards on the essential characteristics that quality assurance systems must have supervision of fulfilling this obligation by service providers. It also comprises the existence of a health technology assessment system that collaborates in the decision-making processes of the entire health system; the use of the scientific methodology to evaluate health interventions of different degrees of complexity; and the use of this system to raise the quality of service provision (23).

The four fundamental aspects are user rights, complex interventions, user satisfaction, and continuous quality improvement.

The goals to achieve in this EPHF are to ensure the availability and accessibility of up-to-date genetic programs, services, tests, and treatments; evaluate the results of available genetic services to determine their effectiveness; review and evaluate information related to the clinical utility and validity of available genetic tests.

Proposed action: Evaluate the effectiveness, accessibility, and quality of personal and population health services in the field of MG. 


\section{EPHF 10: Research}

This EPHF is in constant innovation, ranging from applied research efforts to drive PH practices changes to formal scientific research efforts. The development of own investigation of the sanitary authorities in its different levels; and the establishment of alliances with research centers and academic institutions to carry out studies that support decision-making by national health authorities at all levels and in the broadest scope of their action. Research and innovation are understood as instruments that contribute to improving health, the health system's sustainability and functioning, and the generation of value and socio-economic development.

Research teams. They should be consolidated in MG, oriented to respond to local, national, and regional needs. These teams must be inter-disciplinary and multi-professional. The standard research team composition includes a lead researcher with full training and experience, one or two senior researchers with full postgraduate training, two to three junior researchers in postgraduate training, three or four research assistants in undergraduate training, and one or two research technicians technical and logistical support. A consolidated research team is an autonomous group with one to two research lines established for at least 5 to 10 years. With continuous and progressive research, they actively work in research networks, with two to three continuous and progressive publications per year, with investigative efficiency, concrete contributions to universal knowledge, even if they are small, and the ability to find funds permanently.

Research networks. They are groups of researchers who cooperate and collaborate with a single purpose. They are multiprofessional, inter-disciplinary, multi-institutional, share 1-2 lines of research, where members DO NOT compete with each other, collaborate, cooperate, DO NOT duplicate efforts, complement each other, with rotating leadership, and mutual respect. Besides, they share resources, share results and products, and are continuous, permanent, and progressive.

Research lines. Primary lines: mental retardation and Genetics, prenatal and neonatal diagnosis; prevention of disabilities; Genomics and personalized medicine. Genetic diseases and CD, in general, tend to be multi-systemic and determine chronic physical and mental disorders that seriously compromise the health and quality of life of those affected and their families. The management of these problems is complex and lengthy and requires a multidisciplinary and comprehensive approach.

The goals to achieve in this EPHF are to identify and evaluate the findings of Genetics research to determine the convenience of incorporating them into PH practices; evaluate the social, economic, and ethical impact of this information to determine its suitability for PH; and ensure that genetic information incorporates into the PH.

Proposed action: Implement research of new knowledge and innovative solutions to health problems in MG.

\section{EPHF 11: Reducing the impact of emergencies and disasters}

This function is the planning and executing prevention, mitigation, preparedness, response, and early rehabilitation actions related to PH. For this reason, we have located prevention activities at this point. Difficulties in treatment make prevention a primary goal.

In this field, genetics services' strategies are of two types: (a) care-preventive services based on the affected patient and her family and (b) population-based prevention programs, PH genetics. Perhaps the most crucial action in this section is prevention. The four prevention levels of genetic diseases are pre-conception primary prevention, prevention-based reproductive options, secondary prevention, and tertiary prevention.

The primary prevention of genetic diseases comprises preventing the occurrence of the disorder in question. Since the individual's genetic makeup fixes at conception, genetic diseases' primary prevention must be pre-conception. For example, they are protecting people of reproductive age from exposure to agents capable of damaging genetic material, cytotoxic or teratogenic, or encouraging conceptions to occur at optimal maternal ages, between 20 to 35 years, according to some authors, to reduce the risk of chromosomal abnormalities. Primary disease prevention of hereditary genetic diseases is much more complicated, as this 
would require that there are no marriages of carriers of the same recessive gene or that they have no offspring.

Identification of couples at risk. A form of primary prevention would be the identification of couples at risk of transmitting a genetic disease, followed by offering the voluntary option of reproductive abstention, artificial insemination with a sperm or egg donor, or adoption. Since reproductive autonomy is a fundamental ethical principle, these strategies for the primary prevention of genetic diseases are not very useful. Certain congenital anomalies (particularly neural tube defects) are subject to primary prevention, ensuring adequate folic acid intake before conception. On the other hand, other non-genetic CDs that occur due to teratogens' post-conception action (drugs, radiation, infections, environmental pollutants, and others) can also be the primary prevention object, avoiding exposure to these agents during pregnancy.

Prevention based on reproductive options. Given the difficulties inherent in primary prevention, the most widely used preventive methods throughout the world are based on post-conception reproductive options. This concept implies knowledge of the genetic risk on the part of the couple and the informed and autonomous choice of the preventive option that best suits their values and expectations regarding a future child. The first step is to detect genetic risk factors, that is, the risk that an individual (or couple) develops or transmits a genetic disease, followed by genetic counseling and prenatal diagnosis of the condition in question.

In early pregnancy, an increased risk of chromosomal abnormalities can also be detected non-invasively by maternal age (over 35 years) by measuring biochemical markers (alpha-fetoprotein, chorionic gonadotropin, and estriol) in maternal blood and by fetal ultrasonography. Genetic counseling that follows the detection of increased genetic risk allows individuals and couples to manage risk according to the available options and their values. The counseling is non-directive and seeks to train patients to make their own decisions regarding the genetic risk detected. Possible reproductive decisions include the voluntary option of fetal diagnosis of the condition in question in the first or second trimester of gestation. Prenatal diagnosis contributes to at-risk couples initiating pregnancies that would otherwise be avoided (or, if they occur, terminated) for fear of genetic risk. Prenatal diagnosis reassures most couples with an expected result, as most genetic risks are low in magnitude (1-25\%). Those couples with an abnormal prenatal diagnosis have the option of continuing the pregnancy and better preparing for the birth of an affected child.

Secondary prevention of genetic diseases consists of measures to minimize clinical manifestations in affected patients or people at high risk of being affected in the future. The appropriate measures are the early subclinical detection of diseases or genetic predispositions, followed by preventive and therapeutic interventions. There are numerous examples of these actions, including newborn screening for congenital hypothyroidism and phenylketonuria, replacement therapy for genetic hormone or enzyme deficiencies, or periodic colonoscopy followed by surgery in people who have inherited a colon cancer gene. The discoveries of genetic bases in the predisposition and development of common diseases (diabetes, cancer, epilepsy, coronary heart disease, mental diseases, and others) lead to more effective measures for the prevention and therapeutic management of these conditions. Population-based secondary prevention programs are closely related to clinical genetics services, which are the effectors through which they are implemented.

Tertiary prevention. Most people with genetic diseases and $\mathrm{CD}$ are born without previous warning signs, that is, to parents without high genetic risk. It is clear then that the frequency of these diseases can never be reduced to zero and that health actions in genetics must also include all the services required minimizing the medical, emotional, and social impact that genetic diseases produce on those affected and their families. These include genetic diagnosis services, treatment of genetic ailments, rehabilitation of disabilities, and the best possible adaptation of the patient and her family to the disease in question and society.

The goals to achieve in this EPHF are implementing care-preventive services based on the affected patient and her family and population-based prevention programs in PH genetics.

Proposed action: Implement a public policy in the prevention of genetic conditions. 


\section{Conclusion}

The EPHF guides public health policies in Latin America and Ecuador. From this perspective, medical genetics and genomics must be included as a priority in the country's public policy. In this review, we propose the activities to be implemented in this context. This challenge requires political and scientific leadership.

\section{Compliance with Ethical Standards}

\section{Funding}

The authors declare that the financial resources for this research's preparation do not come from any fund but their selfmanagement.

\section{Conflict of interests}

Author Fabricio González-Andrade declares that he has no conflict of interest. Author Gabriela Aguinaga- Romero declares that she has no conflict of interest

\section{Ethical approval}

This article does not contain any studies with human participants or animals performed by any of the authors.

\section{References}

Aswini, Y. B., \& Varun, S. (2010). Genetics in public health: Rarely explored. Indian journal of human genetics, 16(2), 47-54. https://doi.org/10.4103/09716866.69326

Battista, R. N., Blancquaert, I., Laberge, A. M., van Schendel, N., \& Leduc, N. (2012). Genetics in health care: an overview of current and emerging models. Public health genomics, 15(1), 34-45. https://doi.org/10.1159/000328846

Brand, A., Brand, H., \& Schulte in den Bäumen, T. (2008). The impact of genetics and genomics on public health. European journal of human genetics: EJHG, 16(1), 5-13. https://doi.org/10.1038/sj.ejhg.5201942

Burton, P. R., Tobin, M. D., \& Hopper, J. L. (2005). Key concepts in genetic epidemiology. Lancet, 366(9489), 941-951. https://doi.org/10.1016/S01406736(05)67322-9

Christianson, A., \& Modell, B. (2004). Medical genetics in developing countries. Annual review of genomics and human genetics, 5, 219-265. https://doi.org/10.1146/annurev.genom.5.061903.175935

Conejero, J. S., Godue, C., Gutiérrez, J. F., Valladares, L. M., Rabionet, S., Concha, J., Valdés, M. V., Gómez, R. D., Mujica, O. J., Cabezas, C., Lucano, L. L., \& Castellanos, J. (2013). Competencias esenciales en salud pública: un marco regional para las Américas [Core competencies in public health: a regional framework for the Americas]. Revista panamericana de salud publica = Pan American journal of public health, 34(1), 47-53.

Etchegary, H., Green, J., Parfrey, P., Street, C., \& Pullman, D. (2015). Community engagement with genetics: public perceptions and expectations about genetics research. Health expectations: an international journal of public participation in health care and health policy, 18(5), 1413-1425. https://doi.org/10.1111/hex.12122

González-Andrade, F., \& López-Pulles, R. (2010). Ecuador: public health genomics. Public health genomics, 13(3), 171-180. https://doi.org/10.1159/000249817

González-Andrade, F., \& López-Pulles, R. (2012). Congenital malformations in Ecuadorian children: urgent need to create a National Registry of Birth Defects. The application of clinical genetics, 3, 29-39. https://doi.org/10.2147/tacg.s8794

González-Andrade, F., Aguinaga-Romero, A., Vallejo, F. (2012) Implementation of the National Policy of Genetics in Human Health: axis of a new paradigm in Ecuador. [Implementación de la Política Nacional de Genética en Salud Humana: eje de un nuevo paradigma en Ecuador]. En: Memorias de la Cuba Salud 2012, Convención Internacional de Salud Pública, Reunión Internacional de Genética Comunitaria, Diciembre 2012: 7718-28. ISBN: 978-959-212-811-8 (versión digital). http://www.convencionsalud2012.sld.cu/index.php/convencionsalud/2012/paper/view/2239/799

Halliday, J. L., Collins, V. R., Aitken, M. A., Richards, M. P., \& Olsson, C. A. (2004). Genetics and public health--evolution, or revolution? Journal of epidemiology and community health, 58(11), 894-899. https://doi.org/10.1136/jech.2003.018515

Kaye C. I. (2012). Genetic service delivery: infrastructure, assessment, and information. Public health genomics, 15(3-4), 164-171. https://doi.org/10.1159/000335552

Knottnerus J. A. (2003). Community genetics and community medicine. Family practice, 20(5), 601-606. https://doi.org/10.1093/fampra/cmg519 
Research, Society and Development, v. 10, n. 5, e1610514731, 2021

(CC BY 4.0) | ISSN 2525-3409 | DOI: http://dx.doi.org/10.33448/rsd-v10i5.14731

Monje-Vargas JA (2013). Mission "Manuela Espejo", paradigm of solidarity turned into State policy in Ecuador. [Misión "Manuela Espejo", paradigma de la solidaridad convertida en política de Estado en Ecuador]. Rev Cubana Salud Pública, 39(3): 598-608. http://scielo.sld.cu/scielo.php?script=sci_arttext\&pid=S0864-34662013000300014\&lng=es.

Rogowski, W. H., Grosse, S. D., \& Khoury, M. J. (2009). Challenges of translating genetic tests into clinical and public health practice. Nature reviews. Genetics, 10(7), 489-495. https://doi.org/10.1038/nrg2606

Smerecnik, C. M., Mesters, I., de Vries, N. K., \& de Vries, H. (2009). Alerting the general population to genetic risks: the value of health messages communicating the existence of genetic risk factors for public health promotion. Health psychology: official journal of the Division of Health Psychology, American Psychological Association, 28(6), 734-745. https://doi.org/10.1037/a0016386

Ten Kate L. P. (2005). Community genetics: a bridge between clinical genetics and public health. Community genetics, 8(1), 7-11. https://doi.org/10.1159/000083330

Ten Kate, L. P., Al-Gazali, L., Anand, S., Bittles, A., Cassiman, J. J., Christianson, A., Cornel, M. C., Hamamy, H., Kääriäinen, H., Kristoffersson, U., Marais, D., Penchaszadeh, V. B., Rahman, P., \& Schmidtke, J. (2010). Community genetics. Its definition 2010. Journal of community genetics, 1(1), 19-22. https://doi.org/10.1007/s12687-010-0007-z

Woodhouse, C., Lopez Camelo, J., \& Wehby, G. L. (2014). A comparative analysis of prenatal care and fetal growth in eight South American countries. PloS one, 9(3), e91292. https://doi.org/10.1371/journal.pone.0091292 Castilla, E. E., \& Orioli, I. M. (1986). Prevalence rates of microtia in South America. International journal of epidemiology, 15(3), 364-368. https://doi.org/10.1093/ije/15.3.364

Zwanikken, P. A., Alexander, L., Huong, N. T., Qian, X., Valladares, L. M., Mohamed, N. A., Ying, X. H., Gonzalez-Robledo, M. C., Linh, 1., Wadidi, M. S., Tahir, H., Neupane, S., \& Scherpbier, A. (2014). Validation of public health competencies and impact variables for low- and middle-income countries. BMC public health, 14, 55. https://doi.org/10.1186/1471-2458-14-55 